\title{
Cercanía espacial y distancia temporal entre una unidad doméstica y las estructuras agrícolas adyacentes en el valle de Yocavil
}

\author{
Sonia L. Lanzelotti y Alejandro F. Zucol \\ Recibido 28 de diciembre 2018. Aceptado 21 de junio 2019
}

\begin{abstract}
RESUMEN
Se analiza la estratigrafía y el contenido de microfósiles para evaluar la sucesión de eventos entre una estructura residencial temprana y las estructuras agrícolas adyacentes de la Mesada del Agua Salada (valle de Yocavil, provincia de Catamarca). En el recinto se registraron tres unidades estratigráficas: 1) relleno de nivelación antrópico, 2) nivel de ocupación, y 3) relleno posdepositacional reciente. El perfil de las estructuras agrícolas refleja dos ciclos: uno superior (A), que se dispone sobre un ciclo inferior de horizontes $\mathrm{Ab}-\mathrm{A} / \mathrm{Cb}-\mathrm{Cb}$. El análisis de las asociaciones de microrrestos y de los procesos de formación de cada perfil permite establecer una secuencia de cinco eventos y una correlación entre el piso de ocupación y el material parental del paleosuelo. Se concluye que la ocupación de la unidad residencial es anterior a la construcción y utilización de las estructuras agrícolas.
\end{abstract}

Palabras clave: Agricultura prehispánica; Estratigrafía; Microfósiles.

\begin{abstract}
SPATIAL PROXIMITY AND TEMPORARY DISTANCE BETWEEN A DOMESTIC UNIT AND ADJACENT AGRICULTURAL STRUCTURES IN THE YOCAVIL VALLEY. In this paper, the stratigraphy and content of microfossils are analyzed to evaluate the succession of events relating an early residential structure and the adjacent agricultural structures of the Mesada del Agua Salada, Yocavil valley, Catamarca province. Three stratigraphic units were recorded at the site: 1) anthropic leveling fill; 2) an occupation level; and 3) recent post-deposition fill. The profile of agricultural structures reflects two cycles: an upper one (A), and a lower cycle of horizons, $\mathrm{Ab}-\mathrm{A} / \mathrm{Cb}-\mathrm{Cb}$. The analysis of microfossil associations and formation processes of each profile enabled a sequence of five events to be established and a correlation made between the occupation floor and the parental material of the paleosol. It is concluded that the occupation of the residential unit predates the construction and use of the agricultural structures.
\end{abstract}

Keywords: Prehispanic agriculture; Stratigraphy; Microfossils.

\footnotetext{
Sonia L. Lanzelotti, Instituto de las Culturas, Universidad de Buenos Aires, Consejo Nacional de Investigaciones Científicas y Técnicas (IDECU-UBA-CONICET). Moreno 350 (I09I), Ciudad Autónoma de Buenos Aires, Argentina. Instituto de Investigaciones Geográficas, Universidad Nacional de Luján. Ruta Nac. 5 y Av. Constitución (6700), Luján, Buenos Aires, Argentina. Email: sonia.lanzelotti@conicet.gov.ar

Alejandro F. Zucol, Laboratorio de Paleobotánica, Centro de Investigaciones Científicas y Transferencia de Tecnología a la Producción (CICYTTP-UADER-Provincia de Entre Ríos-CONICET), Dr. Materi y España SN (E3I05BWA), Diamante, Argentina. Email: cidzucol@gmail.com
} 


\section{INTRODUCCIÓN}

La agricultura prehispánica en el Noroeste argentino ha sido reconocida desde los primeros estudios arqueológicos, con base en la existencia de infraestructura agrícola en varios sitios y localidades (Ambrosetti 1897; Bruch 1911; Debenedetti 1918; Ardissone 1928). Sin embargo, la cronología, sus características y cambios a lo largo del tiempo son tema de debate a consecuencia de la dificultad de realizar fechados directos sobre las estructuras agrícolas propiamente dichas (sean canchones, andenes, canales o acequias), o bien para establecer de modo certero la contemporaneidad entre las infraestructuras agrícolas y residenciales (Albeck 2003-2005; Korstanje 2010).

Para el establecimiento de parámetros cronológicos, Albeck (2003-2005) ha desarrollado una metodología basada en tres indicadores: culturales (asociación con viviendas, refugios y sus materiales culturales), tecnológicos (tipo de terreno agrícola, emplazamiento, modalidad constructiva, sistema de riego, sistema de laboreo) y cronológico-relativos (liquenometría, sedimento acumulado entre roca), los cuales le permitieron identificar diversas etapas en la construcción y uso de las estructuras agrícolas en Casabindo y Coctaca. Por otro lado, Korstanje y colaboradoras (2010) experimentaron con la datación de materia orgánica de suelos enterrados bajo grandes despedres en la cuenca de Angastaco y Molinos (Salta), y estimaron así una edad radiocarbónica mínima para el comienzo de construcción de dichos despedres y, con ello, el inicio de la utilización agrícola de los espacios.

Respecto de la caracterización de prácticas agrícolas, ha habido acercamientos desde los estudios de microfósiles y de suelos. Los microrrestos silíceos han demostrado gran potencial en arqueología desde fines de la década de 1970 (Pearsall 1978) y desde entonces fueron utilizados como indicadores para la reconstrucción paleoambiental, la identificación de especies consumidas y el registro de especies cultivadas, entre otros (Korstanje y Babot 2008; Zucol et al. 2008).

Korstanje y colaboradoras (2014) aplicaron una metodología de "análisis múltiple" que integra estudios fitolíticos con análisis de suelos, con la que reconocieron prácticas de riego, abono y quema de rastrojos en sitios del NOA. Por otro lado, la metodología de Sampietro y colaboradores (2014) se basa en estudios geoarqueológicos que permitieron identificar alteraciones antrópicas debido al uso sostenido de los suelos y la utilización de abono en campos agrícolas.

Atento a la diversidad de escalas y problemáticas de investigación, uno o un conjunto de estos proxies pueden resultar herramientas metodológicas útiles para el conocimiento del uso pasado de las estructuras agrícolas, sin que constituyan metodologías universales. Las características arqueológicas y la historia ambiental de cada lugar pueden requerir ensayos metodológicos específicos.

El presente trabajo se diseñó con el propósito de establecer, en la Mesada del Agua Salada (vaIle de Yocavil, provincia de Catamarca), la posible contemporaneidad entre el piso de ocupación de una unidad arquitectónica de tipo habitacional y el suelo desarrollado en las estructuras agrícolas adyacentes, utilizando el análisis estratigráfico y de contenido de microrrestos silíceos -principalmente fitolitos- como línea de evidencia. Se trata de un estudio realizado a escala local, orientado a profundizar el conocimiento acerca de los procesos de ocupación y reocupación de este espacio a lo largo del tiempo desde la perspectiva de la arqueología del paisaje (sensu Criado Boado 1991), acercamiento teórico que viene siendo aplicado satisfactoriamente para comprender la compleja historia ocupacional del valle de Caspinchango (Lanzelotti 2012; Lanzelotti y Spano 2015).

\section{La Mesada del Agua Salada}

Se trata de un área arqueológica que se ubica en la zona pedemontana de la sierra del Aconquija, a unos $13 \mathrm{~km}$ al sudeste de la localidad de Santa María, en la provincia de Catamarca (Figura 1.1). Abarca una superficie de 101,3 ha, con una altitud mínima de 2600 msnm y máxima de 3000 msnm, cuyos límites norte y sur son ríos encajonados, de régimen permanente. La vegetación corresponde mayormente a la provincia Fitogeográfica Prepuneña del Dominio Chaqueño (sensu Cabrera y Willink 1980), o provincia del Monte de la Zona transicional de América del Sur (sensu Morrone y Ezcurra 2016), caracterizada por la presencia de cactáceas columnares de gran tamaño y una escasa presencia de especies del género Larrea, aunque, a consecuencia del relieve, se observan algunos elementos de las provincias Altoandina y Puneña hacia el este y provincia del Monte hacia el oeste (Morláns 1995). En términos geomorfológicos, está conformada por depósitos de terraza de piedemonte, aluviales de torrente y flujos detríticos del período Cuaternario (Ruiz Huidobro 
1972; González et al. 2000). Estudios paleoambientales -si bien escasos y de escala espacio-temporal amplia- indican para la región períodos de mayor o menor humedad y temperatura media anual a lo largo del Holoceno tardío, con condiciones más húmedas que las actuales para el primer milenio de la Era y el establecimiento de condiciones más secas

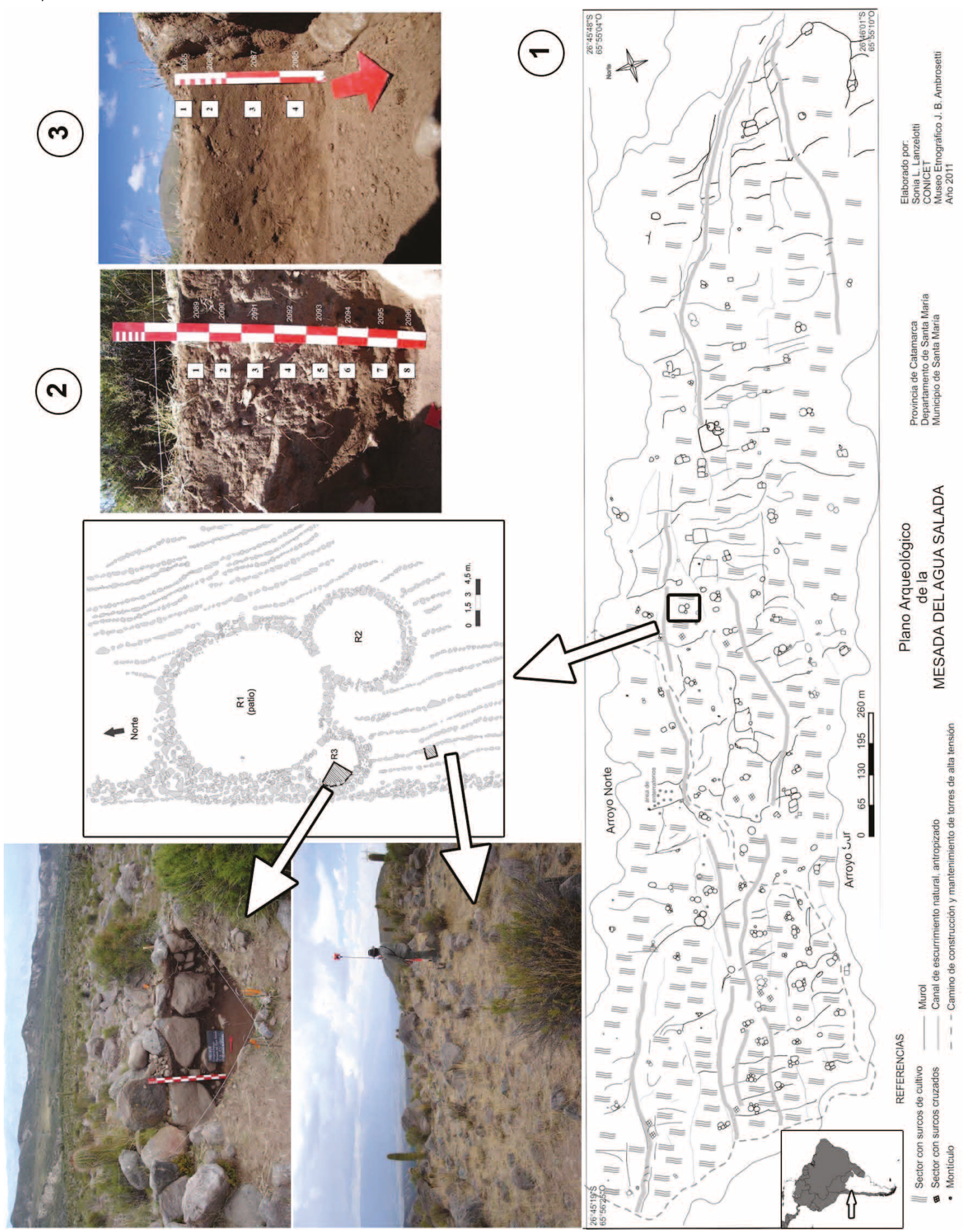

poco antes del siglo X (Garralla 2003). Para el segundo milenio, se registran varias fluctuaciones hacia una mayor humedad, relacionadas con eventos de mayor alcance -como la Pequeña Edad de Hielo- y el retorno, en tiempos recientes, a las condiciones climáticas actuales mayormente secas (Peña-Monné et al. 2015). 
El lugar también es conocido como "Yacimiento El Ciénago" en función del trabajo de Arocena y colaboradoras (1960), quienes lo definieron como un sector de viviendas dispersas entre cuadros de cultivo del período Agroalfarero temprano o Formativo (sensu González 1955 y Núñez Regueiro 1974, respectivamente), que en el valle de Santa María habría abarcado todo el primer milenio de la Era (Scattolin 2007).

Un relevamiento detallado de la evidencia arquitectónico-arqueológica realizado a partir del año 2008 permitió registrar 151 unidades arquitectónicas cerradas y dispersas que incluyen: 94 unidades habitacionales, 44 unidades de probable funcionalidad productiva (corrales o recintos de siembra), once estructuras de almacenamiento o tumbas y una represa (Lanzelotti 2011, 2012). La infraestructura agrícola incluye obras de riego (represa, acequias y canales), estructuras de cultivo propiamente dichas (andenes y líneas paralelas de piedra, recintos y retículos, muros divisores/despedres lineales y canales de escurrimiento antropizados), despedres circulares y pequeños montículos adosados a estructuras habitacionales. La mayoría de estas últimas corresponden al patrón Tafí (sensu Berberián y Nielsen 1988). El material cerámico de superficie incluye tanto estilos tempranos como tardíos, coloniales y subactuales. Excavaciones arqueológicas permitieron obtener dataciones radiocarbónicas para el piso de ocupación de dos unidades arquitectónicas, que arrojaron un fechado de $1394 \pm 39$ AP y otro de $642 \pm 42$ AP (Lanzelotti y Spano 2015).

Este contexto plantea que la asignación cronológica de las abundantes estructuras de cultivo es ambigua, puesto que podrían ser contemporáneas con las unidades residenciales tempranas, pero también pueden haber sido modificadas, reutilizadas o directamente construidas por las sociedades del Tardío.

\section{MATERIALES Y MÉTODOS}

Se realizaron análisis estratigráficos, sedimentológicos y de contenido de microfósiles en dos columnas estratigráficas: una realizada a partir del perfil de excavación de una estructura residencial (PR) denominada U48-R3; y una segunda columna correspondiente al perfil de suelo (PS) relevado en estructuras agrícolas adyacentes a la estructura residencial (Figura 1).

\section{Estructura residencial}

U48-R3 corresponde a uno de los dos recintos circulares adosados a un patio central que conforman la Unidad 48. Se excavó el cuadrante sudoeste (Lanzelotti y Spano 2015), en cuyo perfil se observaron tres unidades estratigráficas: una superior de $0,34 \mathrm{~m}$ de potencia, que corresponde al relleno posocupacional del recinto; otra de $0,26 \mathrm{~m}$, que corresponde al nivel de ocupación; y una basal de $0,20 \mathrm{~m}$ de potencia, correspondiente al relleno generado antrópicamente para la nivelación de la superficie del recinto durante su construcción. El material cerámico de la excavación corresponde a estilos asignables a momentos previos al 1000 AD. Los líticos fueron analizados por Carbonelli (2012), y los restos óseos, por Belotti (2013). De aquí procede el mencionado fechado radiocarbónico, que arrojó una edad de $1394 \pm 39$ AP (Lanzelotti y Spano 2015).

La caracterización sedimentológica se realizó en el Laboratorio de Suelos de la Universidad Nacional de Catamarca. En el perfil NNE se tomaron muestras de microfósiles cada $10 \mathrm{~cm}$ de profundidad a fin de detectar posibles cambios al interior de las tres unidades estratigráficas.

\section{Estructuras agrícolas}

Se trata de andenes con subdivisiones menores de líneas de piedra simple que delimitan surcos de cultivo, descriptos en Lanzelotti y Lamamí (2010) y Lanzelotti (2012). Estas líneas de piedra tienen una separación media de $1 \mathrm{~m}$, y solo dos o a lo sumo tres hiladas de roca, de las cuales únicamente asoma la parte superior. En sentido longitudinal, las líneas de piedra determinan una pendiente de 1,6\%.

La calicata se excavó a una distancia de $5 \mathrm{~m}$ al sur de U48-R3. Las unidades identificadas fueron interpretadas desde una perspectiva pedoestratigráfica y geoarqueológica (Waters 1992; Soil Survey Staff 1999) y se tomaron muestras para análisis fisicoquímicos (1 kg por muestra, enviado al Laboratorio de Suelos de la Universidad Nacional de Catamarca), y muestras de puño para análisis de microfósiles.

\section{Microfósiles}

Las muestras fueron ingresadas en el Repositorio del Laboratorio de Procesamiento de material sedimentológico-paleontológico del 
CICYTTP-Diamante (CONICET) bajo el ID detaIlado en las Tablas 1 y 2.

Tras un submuestreo mediante cuartos, la prospección y estudio de los microrrestos se realizó aplicando las pautas metodológicas convencionales utilizadas para la concentración de biominerales en materiales clásticos (Bonomo et al. 2009) con ciertas precauciones principalmente orientadas a la conservación y concentración de elementos formados por materia orgánica resistente tales como cutina y esporopolenina. La separación granulométrica se realizó en una fracción más fina (menor de $5 \mu \mathrm{m}$ de diámetro) por sifonado; una fracción gruesa (mayor de $250 \mu \mathrm{m}$ de diámetro) por tamizado; en tanto que la fracción de 5 a 250 um de diámetro restante es la que se utilizó para la separación densimétrica en dos fracciones granulométricas obtenidas por tamizado en húmedo: 5-53 $\mu \mathrm{m}$ y 53-250 $\mu \mathrm{m}$. Con estas últimas se realizó la separación densimétrica, mediante la utilización de solución acuosa de politungstato de sodio (peso específico 2,3). Los concentrados fueron montados en bálsamo de Canadá y en aceite de cedro.
Las observaciones microscópicas fueron realizadas con un microscopio Nikon Eclipse E200 y las fotografías fueron obtenidas con una cámara digital Nikon Coolpix 990. Los preparados microscópicos fueron incorporados a la Colección del Laboratorio de Paleobotánica del CICYTTP. Diamante (CDPalbo-mic).

Las formas fitolíticas se tomaron sobre la base de una muestra mínima representativa de 450 elementos recontados por muestra analizada. Estos valores fueron analizados comparativamente y graficados en diagramas fitolíticos mediante la utilización del paquete de software POLPAL (Walanus y Nalepka 1999, 2002), el cual permitió también el análisis de la rarefacción de taxa en cada muestra sobre la base de la sumatoria de las probabilidades de cada taxón y la obtención del dendrograma mediante el método de constrained single link cluster analysis (Grimm 1987).

Los principales elementos identificados corresponden a: microcarbones, diatomeas, espículas de espongiarios, estomatocistes de Chrysostomataceae y placas marrones a negras con perforaciones pre-

\begin{tabular}{|c|c|c|c|c|c|c|c|c|c|c|}
\hline \multicolumn{2}{|c|}{ Denominación } & \multicolumn{4}{|c|}{ Descripción de campo } & \multicolumn{5}{|c|}{ Análisis físico-químico } \\
\hline \multirow{4}{*}{$\begin{array}{c}\text { Muestra } \\
\mathrm{N}^{\circ}\end{array}$} & \multirow{4}{*}{$\begin{array}{l}\mathrm{N}^{\circ} \text { Lab. } \\
\text { CICYTTP }\end{array}$} & \multirow{4}{*}{$\begin{array}{l}\text { Profun- } \\
\text { didad } \\
(\mathbf{c m})\end{array}$} & \multirow{4}{*}{$\begin{array}{l}\text { Interpre- } \\
\text { tación }\end{array}$} & $\begin{array}{c}\text { Límite } \\
\text { inferior }\end{array}$ & Estructura & \multirow{4}{*}{$\begin{array}{l}\text { Clase } \\
\text { textural }\end{array}$} & \multirow{4}{*}{$\mathrm{pH}$} & \multirow{4}{*}{$\begin{array}{c}\text { Materia } \\
\text { orgánica } \\
(\%)\end{array}$} & \multirow{4}{*}{$\begin{array}{c}\text { Nitró- } \\
\text { geno } \\
(\%)\end{array}$} & \multirow{4}{*}{$\begin{array}{c}\text { Fósforo } \\
\text { (ppm) }\end{array}$} \\
\hline & & & & Tipo & Tipo & & & & & \\
\hline & & & & & Clase & & & & & \\
\hline & & & & Forma & Grado & & & & & \\
\hline \multirow{3}{*}{1} & \multirow{3}{*}{2085} & \multirow{3}{*}{0 a 3} & \multirow{3}{*}{ A } & abrupto & ausente & \multirow{3}{*}{$\mathrm{Ar}-\mathrm{Fr}$} & \multirow{3}{*}{6,05} & \multirow{3}{*}{1,49} & \multirow{3}{*}{0,05} & \multirow{3}{*}{14,65} \\
\hline & & & & \multirow{2}{*}{ recto } & ausente & & & & & \\
\hline & & & & & ausente & & & & & \\
\hline \multirow{3}{*}{2} & \multirow{3}{*}{2086} & \multirow{3}{*}{3 a 14} & \multirow{3}{*}{$\mathrm{Ab}$} & claro & migajosa & \multirow{3}{*}{ Fr-Ar } & \multirow{3}{*}{7,52} & \multirow{3}{*}{1,99} & \multirow{3}{*}{0,05} & \multirow{3}{*}{3,38} \\
\hline & & & & \multirow{2}{*}{ suave } & fina & & & & & \\
\hline & & & & & moderada & & & & & \\
\hline \multirow{3}{*}{3} & \multirow{3}{*}{2087} & \multirow{3}{*}{14 a 22} & & gradual & migajosa & & & & & \\
\hline & & & $\mathrm{ACb}$ & & fina & $\mathrm{Fr}-\mathrm{Ar}$ & 7,59 & 0,9 & 0,04 & 8,87 \\
\hline & & & & suave & débil & & & & & \\
\hline & & & & $\mathrm{n} / \mathrm{o}$ & ausente & & & & & \\
\hline 4 & 2088 & $\begin{array}{c}22 \mathrm{en} \\
\text { adelante }\end{array}$ & C & $n / 0$ & ausente & $\mathrm{Fr}-\mathrm{Ar}$ & 7,23 & 0,71 & 0,04 & 7,56 \\
\hline & & & & $n / O$ & ausente & & & & & \\
\hline
\end{tabular}

Nota: Ar-Fr: Areno-franco y Fr-Ar: Franco-arenoso.

Tabla 1. Datos de campo y de laboratorio de las unidades relevadas en el PS.

\begin{tabular}{|c|c|c|c|c|c|c|c|c|}
\hline \multicolumn{2}{|c|}{ Denominación } & \multicolumn{2}{|c|}{ Descripción de campo } & \multicolumn{5}{|c|}{ Análisis físico-químico } \\
\hline $\begin{array}{c}\text { Muestra } \\
\mathrm{N}^{\circ}\end{array}$ & $\begin{array}{l}N^{\circ} \text { Lab. } \\
\text { CICYTTP }\end{array}$ & $\begin{array}{l}\text { Profundidad } \\
(\mathrm{cm})\end{array}$ & Interpretación & $\begin{array}{c}\text { Clase } \\
\text { textural }\end{array}$ & $\mathrm{pH}$ & $\begin{array}{c}\text { Materia } \\
\text { orgánica }\end{array}$ & Nitrógeno & $\begin{array}{c}\text { Fósforo } \\
\text { (ppm) }\end{array}$ \\
\hline 1 & 2089 & 0 a 10 & \multirow{4}{*}{$\begin{array}{l}\text { Relleno } \\
\text { posdepositacional }\end{array}$} & \multirow{2}{*}{ Fr-Ar } & \multirow{2}{*}{6,9} & \multirow{2}{*}{2,03} & \multirow{2}{*}{0,09} & \multirow{2}{*}{29,04} \\
\hline \multirow{2}{*}{2} & \multirow{2}{*}{2090} & \multirow{2}{*}{10 a 20} & & & & & & \\
\hline & & & & \multirow{2}{*}{$\mathrm{Fr}-\mathrm{Ar}$} & \multirow{2}{*}{7,7} & \multirow{2}{*}{2,18} & \multirow{2}{*}{0,05} & \multirow{2}{*}{22,88} \\
\hline 3 & 2091 & 20 a 30 & & & & & & \\
\hline 4 & 2092 & 30 a 40 & \multirow{3}{*}{ Niveles de ocupación } & $\mathrm{N} / \mathrm{C}$ & $\mathrm{N} / \mathrm{C}$ & $\mathrm{N} / \mathrm{C}$ & $\mathrm{N} / \mathrm{C}$ & $\mathrm{N} / \mathrm{C}$ \\
\hline 5 & 2093 & 40 a 50 & & \multirow{2}{*}{ Fr-Ar } & \multirow{2}{*}{8,04} & \multirow{2}{*}{2,03} & \multirow{2}{*}{0,10} & \multirow{2}{*}{29,22} \\
\hline 6 & 2094 & 50 a 60 & & & & & & \\
\hline 7 & 2095 & 60 a 70 & \multirow{2}{*}{$\begin{array}{l}\text { Relleno de nivelación } \\
\text { antrópico }\end{array}$} & \multirow{2}{*}{$\mathrm{Fr}-\mathrm{Ar}$} & \multirow{2}{*}{8,1} & \multirow{2}{*}{0,43} & \multirow{2}{*}{0,06} & \multirow{2}{*}{39,05} \\
\hline 8 & 2096 & 70 a 80 & & & & & & \\
\hline
\end{tabular}

Nota: Ar-Fr: Areno-franco y Fr-Ar: Franco-arenoso.

Tabla 2. Datos de campo y de laboratorio de las unidades relevadas en el PR suntamente quitinosas. Respecto de los fitolitos, se contabilizaron multicelulares y unicelulares. En los primeros se describieron afinidades en caso de contar con caracteres diagnósticos, y en los segundos se definieron morfotipos y se reunieron en grupos mayores (Figura 2) siguiendo las descripciones de Mercader y colaboradores (2009), Collura y Neumann (2016), Mercader y colaboradores (2010), Neumann y colaboradores (2016), para establecer sus afinidades botánicas. 


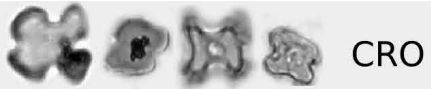
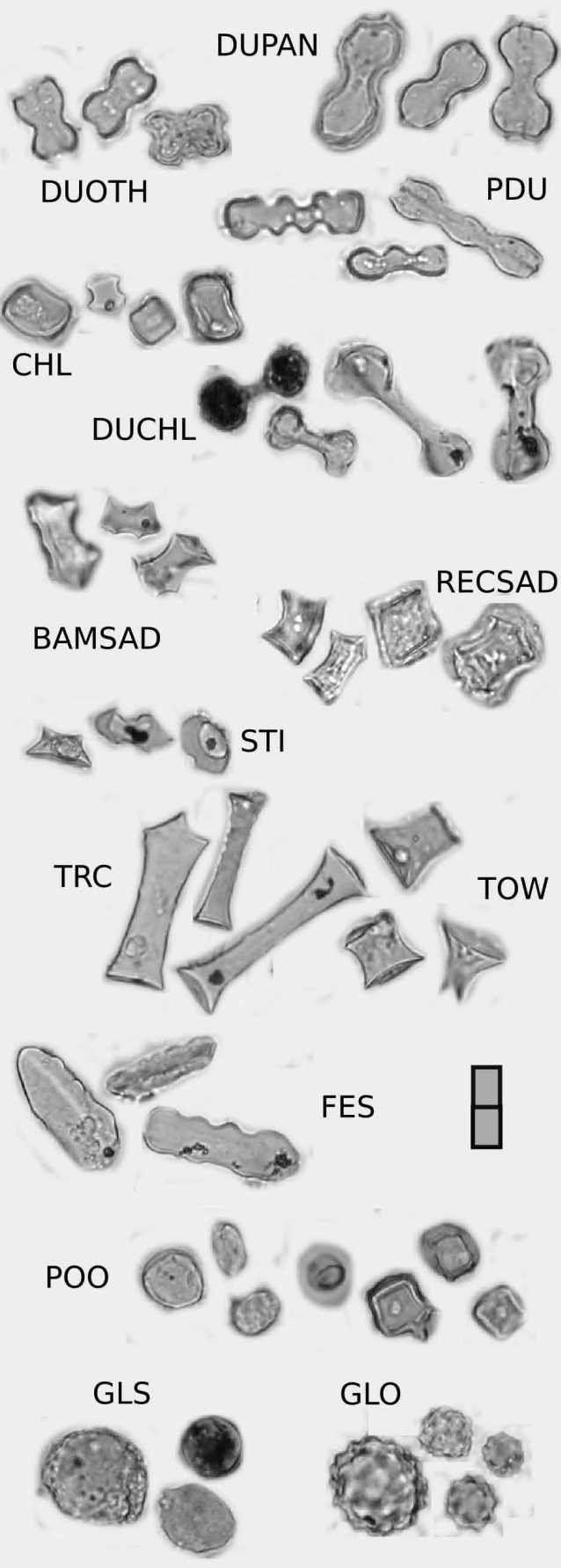

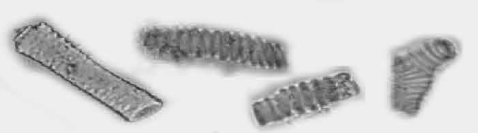

CEL
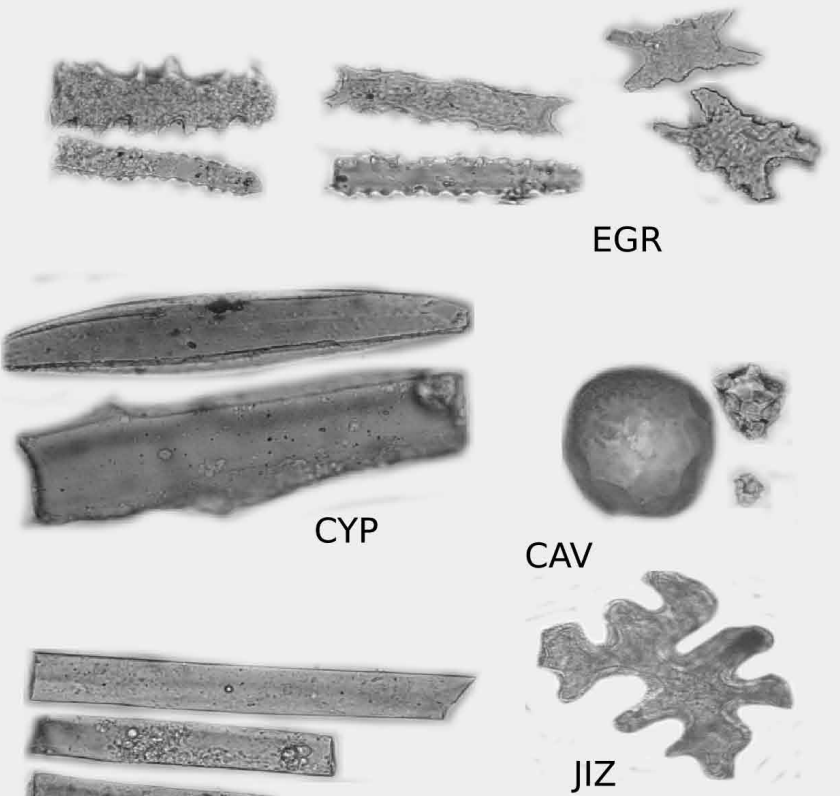

ELL
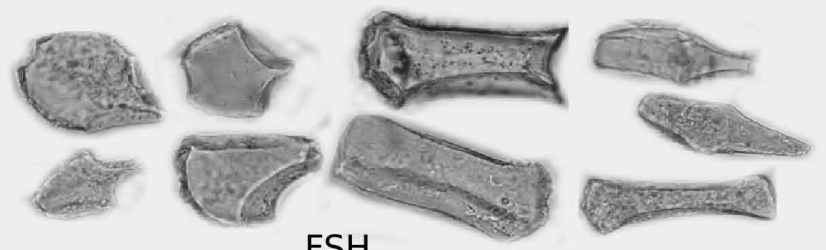

FSH
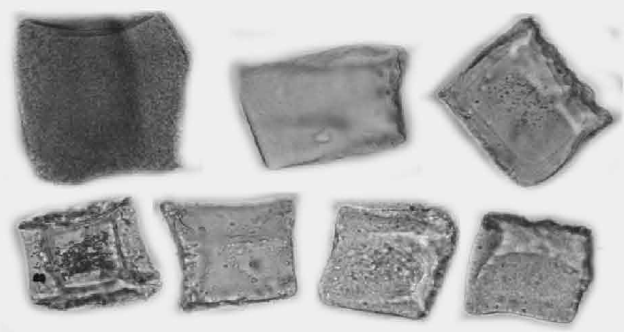

日

$\mathrm{POLB} / \mathrm{S}$

PSH

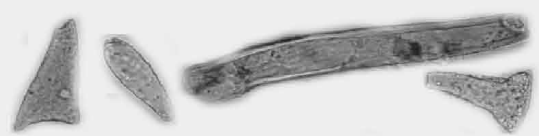

Figura 2. Grupos de morfotipos fitolíticos y los acrónimos utilizados de acuerdo con sus tamaños (izquierda: microfitolitos; derecha: macrofitolitos; escala gráfica en ambos: $20 \mu \mathrm{m}$ ). Acrónimos: CRO (Cross/cruces); DUPAN (Panicoid dumbbell/halterios panicoides); DUOTH (Other dumbbell/otros halterios); PDU (Plurilobular dumbbell/halterios plurilobulados); $\mathrm{CHL}$ (Chloridoid saddle/silla de montar chloridoideas); DUCHL (Chloridoid dumbbell/halterios chloridoideos); BAMSAD (Collapsed saddle/ silla de montar colapsada o bambusoides); RECSAD (Rectangular saddle/ sillas de montar rectangulares); STI (Stipa-type dumbbel//halterio tipo stipoideo); TRC (Truncated cones/conos truncados); TOW (Towers/en forma de torres); FES (Festucoid or boat-types/en forma de bote); POO (Pooid types [crescent, circular, square])Atipos pooideos (en forma de luna creciente, redondeados, cuadrados); CEL (Conduction elements phytoliths/fitolitos originados en elementos de conducción); DICOT JIZ (Puzzle type/en forma de pieza de rompecabezas); CAV (Cavate [irregular, isodiametric and elongate with faceted surface]/ elementos de superficie cavada); GLS (Globular with smooth, granulate or corrugate surface/ Globulares de superficie lisa, granular o corrugada); GLO (Globular with equinate surface/Globular de superficie espinosa); CYP (Cyperoid types [conical, laminar with pentagonal or hexagonal contour, elongate, stellate])Aipos ciperoides (cónicos, laminar de contorno hexagonal o pentagonal, elongados, estrellados); EGR (Elongate grass phytoliths/elongados con afinidad graminoide); FSH (Fan-shapedl en forma de abanico); POLB (Big Parallelepiped or polyhedral/poliédricos de mayor tamaño); POLS (Small Parallelepiped or polyhedral/poliédricos de menor tamaño); PSH (Point-shaped/formas aguzadas); ELS (Small elongate/elongados pequeños); ELL (Large elongate/elongados de mayor tamaño). Referencias en el texto. 
El análisis comparativo de las muestras de ambos perfiles se realizó aplicando análisis numéricos multivariados, en particular el cluster analysis y análisis de correspondencia (DCA Detrented Correspondence Analysis sensu Hill y Gauch 1980), utilizando el programa PAST (Hammer et al. 2001).

\section{RESULTADOS}

Las Tablas 1 y 2 presentan la descripción de campo y de laboratorio de cada columna estratigráfica. La cuantificación por tipo de microrresto se presenta en la Figura 3.1. La descripción de cada perfil integrando las evidencias se presenta a continuación.

\section{Perfil de suelo (PS)}

Desde el punto de vista pedoestratigráfico se reconocen dos ciclos, uno superior de horizonte $\mathrm{A}$ (muestra 2085) de textura areno-arcillosa y escaso desarrollo, que se dispone mediante una discontinuidad litológica sobre un ciclo inferior de horizontes Ab-A/Cb-Cb (muestras 2086, 2087 y 2088). El análisis fisicoquímico de la secuencia refuerza esta interpretación, con cambios notables en textura y estructura, en valores de $\mathrm{pH}$, materia orgánica y fósforo (Tabla 1).

Respecto de los microrrestos (Figura 3.1B), se observa una marcada diferencia entre la muestra superficial (2085), y la subsuperficial (2086) con las inferiores (2087 y 2088), con mayor abundancia relativa de diatomeas, esporomorfos y placas perforadas de naturaleza desconocida (Figura 3.2) en la muestra superficial, que decrecen en la subsuperficial y resultan ausentes en las inferiores, donde se observa una mayor presencia de espículas y microcarbones.

Los fitolitos multicelulares aparecen en similares proporciones a lo largo del perfil, principalmente conformados por elementos epidérmicos y subepidérmicos de afinidad graminoide, compuestos por células largas, cortas, poliédricas y buliformes silicificadas (Figura 3.3B).

Las asociaciones fitolíticas (Figura 3.1B) permiten establecer una marcada similitud entre las muestras superiores (2085 y 2086), indicada por la presencia de distintos tipos de fitolitos en forma de silla de montar, cruces, halterios en sus distintos grupos y globulares. En contraparte, la sección inferior (muestras 2087 y 2088) se caracteriza en forma conjunta por una menor abundancia de estos fitolitos y un marcado incremento de los fitolitos en forma de abanico y los poliédricos, conjuntamente con fitolitos estipoides, pooides y conos truncados y formas de torre, que se encuentran en forma muy abundante en la muestra 2087; la muestra inferior (2088) presentó una menor abundancia de tipos fitolíticos, en especial, de formas diagnósticas.

Se observan ciertos morfotipos presentes en forma homogénea a lo largo de todo el perfil, tales como distintos tipos de fitolitos aguzados, prismáticos cortos, en forma de abanico, poliédricos y elongados; entre los fitolitos diagnósticos, los tipos de cruces, halteriformes y redondeados a elípticos también se encontraron presentes en todas las muestras.

De acuerdo con el cluster analysis, los elementos panicoides caracterizan todo el perfil, mientras que otros elementos megatérmicos de condiciones secas (chloridoides) solo se presentan en los niveles superficiales, y los micro/mesotérmicos (tales como los pooides y estipoides) resultaron abundantes solo en la muestra 2087.

La zona superficial presenta la mayor variabilidad de elementos, si bien su composición marca un sesgo con una mayor presencia de elementos chloridoides, panicoides, bambusoides y elementos globulares. Esta zona se caracteriza por la presencia de distintos elementos en forma de silla de montar que presentan un incremento en sus abundancias hacia el nivel superficial; algunos tipos de fitolitos aguzados, halteriformes, en forma de abanico y globulares esféricos espinosos.

La muestra superficial también presentó morfotipos exclusivos de este nivel, si bien en forma más escasa que la muestra subyacente, siendo fitolitos halteriformes, aguzados, en forma de cono truncado, redondeados y en forma de placas hexagonales.

De acuerdo con estos resultados, puede inferirse que los niveles inferiores del PS se vincularon más a una vegetación herbácea dominada por elementos pooides-festucoides, estipoides y danthonioides, de características climáticas o microclimáticas frías o condiciones de crecimiento adversas, siendo la muestra 2087 la que expresa mejor estas características. 
El grupo de muestras superficiales se vincula con una vegetación de características más cálidas, lo que hace posible estimar que la muestra superficial presenta menores condiciones de disponibilidad hídrica, con elementos panicoides, chloridoideos, como así también bambusoideos y arecoideos.

Cabe destacar que algunos elementos de afinidad panicoide, y en particular, la presencia de

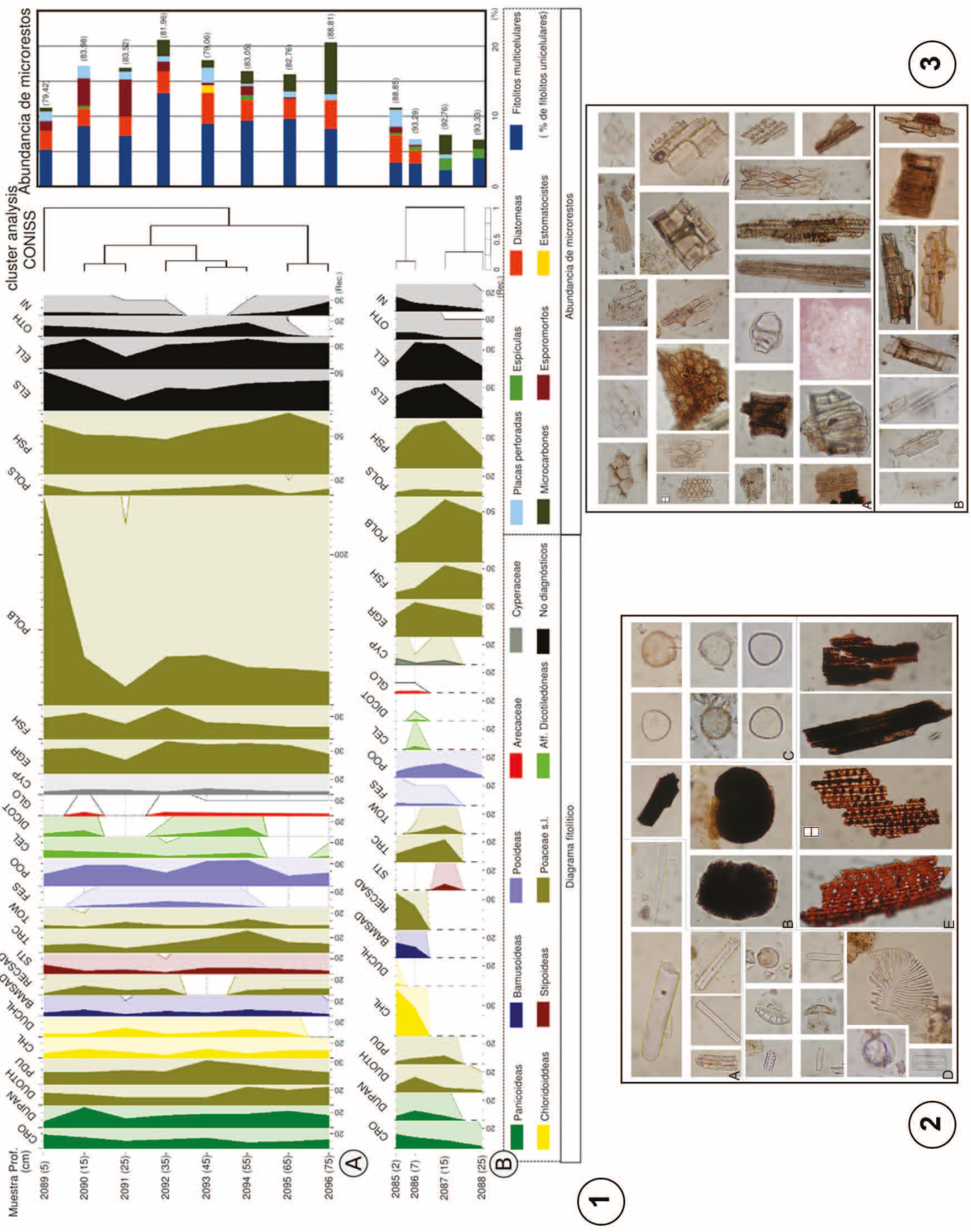

Figura 3. (1) Diagrama fitolítico y abundancia porcentual de microrrestos del PR (A) y PS (B); en tonalidad más clara, exageración de la abundancia (factor $5 \mathrm{x}$ ) y cluster analysis de las asociaciones (Detrented cluster analysis); (2) Microrrestos no fitolíticos hallados en los perfiles analizados (escala gráfica en E: $20 \mu \mathrm{m}$ ): (A) Fragmentos de espículas de espongiarios; (B) Fragmento de material carbonoso; (C) Esporomorfos; (D) Diatomeas; (E) Placas marrones a negras con perforaciones. (3) Fitolitos multicelulares de afinidad graminoide y dicotiledónea del perfil de la estructura residencial (A) y del perfil del área de cultivo (B) Escala gráfica: $20 \mu \mathrm{m}$. 
cruces y elementos halteriformes replegados resultaron ubicuos, con una abundancia que, si bien se incrementó hacia el tope del perfil, fue representativa en todas las muestras.

\section{Perfil de unidad residencial (PR)}

Como mencionamos, la excavación arqueológica de este recinto permitió identificar tres unidades estratigráficas (Lanzelotti y Spano 2015): la unidad superior refleja procesos de sedimentación natural que ocurrieron con posterioridad al abandono del recinto (muestras 2089, 2090 y 2091); la unidad media corresponde al nivel de ocupación donde se realizaron diversas actividades cotidianas (muestras 2092, 2093 y 2094); y la inferior corresponde a la nivelación del terreno realizada con motivo de la construcción del recinto (muestras 2095 y 2096). El análisis sedimentológico arrojó una textura homogénea en las tres unidades, en tanto que los valores $\mathrm{pH}$ muestran un incremento entre el relleno posocupacional y las unidades antrópicas (Tabla 2). El porcentaje de materia orgánica es muy escaso en el depósito inferior; se incrementa en el piso de ocupación, y en el relleno posocupacional se mantiene en niveles cercanos, favorecido probablemente por el desarrollo de vegetación.

Entre los microrrestos no fitolíticos, las diatomeas y placas marrones con perforaciones resultaron abundantes en todos los niveles, mientras que los esporomorfos se presentaron principalmente en la sección media superior, y los microcarbones, en la sección media inferior, los cuales, en muchos casos, son fragmentos angulosos como los observados en el PS, pero en otros son fragmentos esféricos, siendo las muestras 2092 y 2093 en las que no quedan claras estas tendencias y a partir de las cuales se producen estos cambios. Las espículas de espongiarios y los estomatocistes resultaron raras y de presencia ocasional en algunos de los niveles, mientras que los esporomorfos se conformaron principalmente por esporas triletes (Figura 3.1.A).

Los fitolitos multicelulares poseen una mayor abundancia en relación con el perfil PS, y una mayor variabilidad de formas y composición (Figura 3.3.A). Entre los elementos constitutivos de estos fitolitos multicelulares se observan fragmentos epidérmicos y subepidérmicos de afinidad graminoide, epidérmicos de dicotiledóneas; también elementos de conducción articulados y fragmentos de tejido esclerenquimático.
El análisis de los fitolitos unicelulares muestra una diferenciación en una sección inferior (muestras 2095 y 2096) y una sección medio-superior donde se observa claramente la vinculación de las muestras medias (2092, 2093 y 2094) y las muestras superiores (tanto 2091 y 2090, como 2089).

En lo referente a la composición y diferenciación de estos conjuntos (Figura 3.1A), elementos que en el PS caracterizan algunas muestras, tales como los principales elementos diagnósticos de los grupos chloridoides, bambusoides, panicoides, danthonioides, pooides-festucoides y estipoides, se encuentran presentes a lo largo de todo el PR. Dada la gran abundancia y variabilidad de elementos, la agrupación de las asociaciones fitolíticas se fundamenta en variaciones de abundancia relativa de sus elementos. Por esta razón y con la finalidad de establecer la correlación de estas asociaciones fitolíticas, se realizó un análisis de cluster sin considerar su posicionamiento estratigráfico (Figura 4.1.A). Así se puede observar la presencia de dos muestras de composición diferencial a las restantes: la superficial 2089, que presenta la mayor variabilidad de componentes, y la 2091, una de las que poseen menor abundancia y variabilidad de componentes. Este análisis también muestra una vinculación entre las muestras basales (relleno de nivelación del terreno, muestras 2095 y 2096 vinculadas con la 2094); como así también las de los niveles de ocupación (2092, 2093, asociadas sin considerar el piso consolidado 2091) con el restante nivel posocupacional (muestra 2090).

A fines de contrastar estos agrupamientos con las asociaciones fitolíticas del perfil PS, se realizó un análisis de correspondencia de todas las asociaciones (Figura 4.1.B). Su resultado permitió establecer una marcada afinidad entre las muestras del nivel de ocupación del PR (2090-2093) con el nivel intermedio del PS (2087), con base en la marcada abundancia de elementos meso/ microtérmicos (especialmente conos truncados, en forma de torres, halterios estipoideos, plurilobulados, festucoides y pooides), algo diferenciadas de la muestra basal del PS (2088), con baja abundancia de morfotipos diagnósticos y escasa variabilidad. La muestra superficial del PR (2089) se presenta claramente diferenciada de las demás como consecuencia de una mayor rarefacción en su composición; en este mismo sentido, si bien varía su composición, se observan diferenciadas las muestras superficiales del PS (2085 y 2086). Respecto del grupo de muestras pertenecientes al 

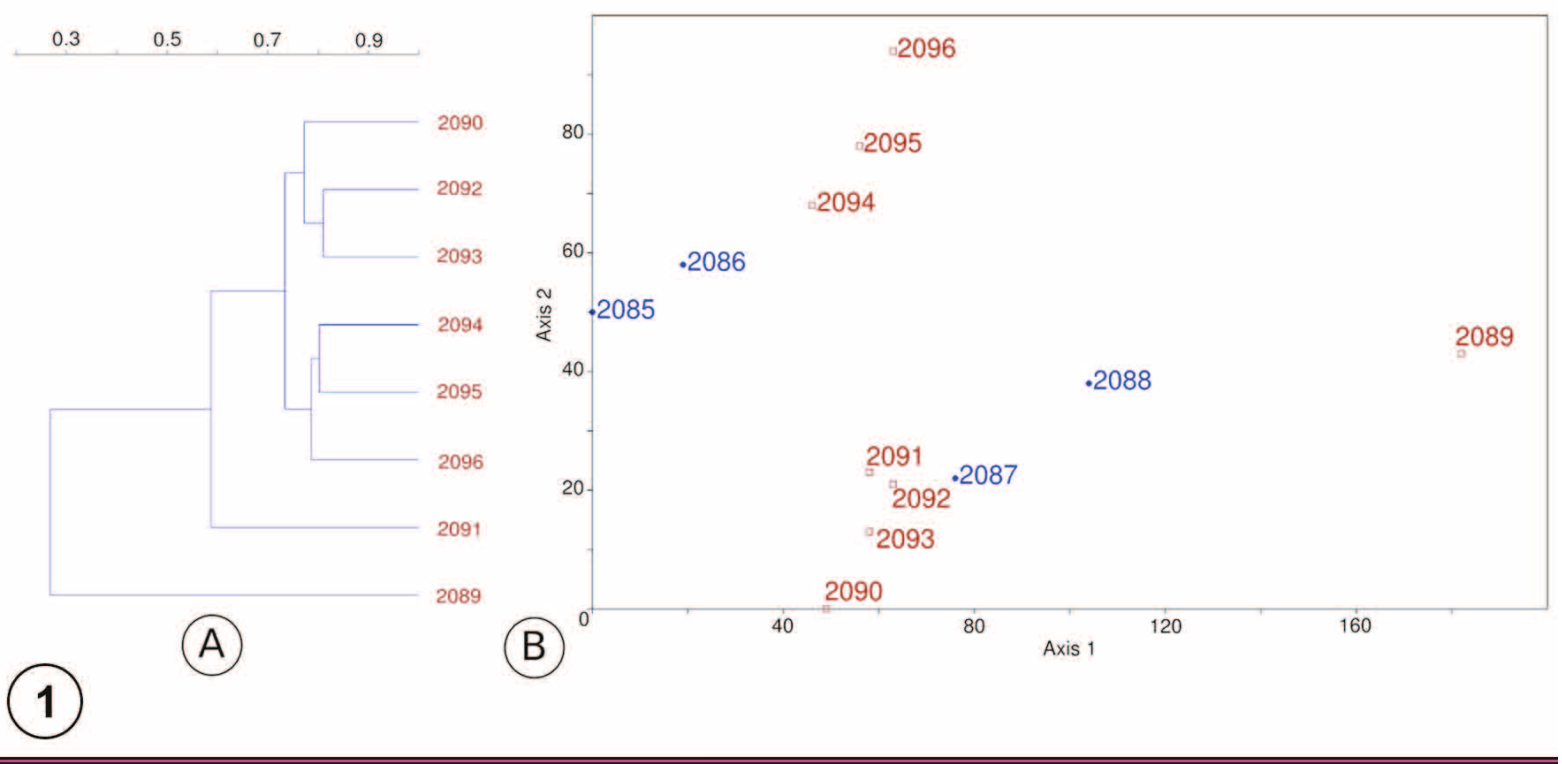

\section{2}

Perfil U48-R3

Perfil estructura agrícola

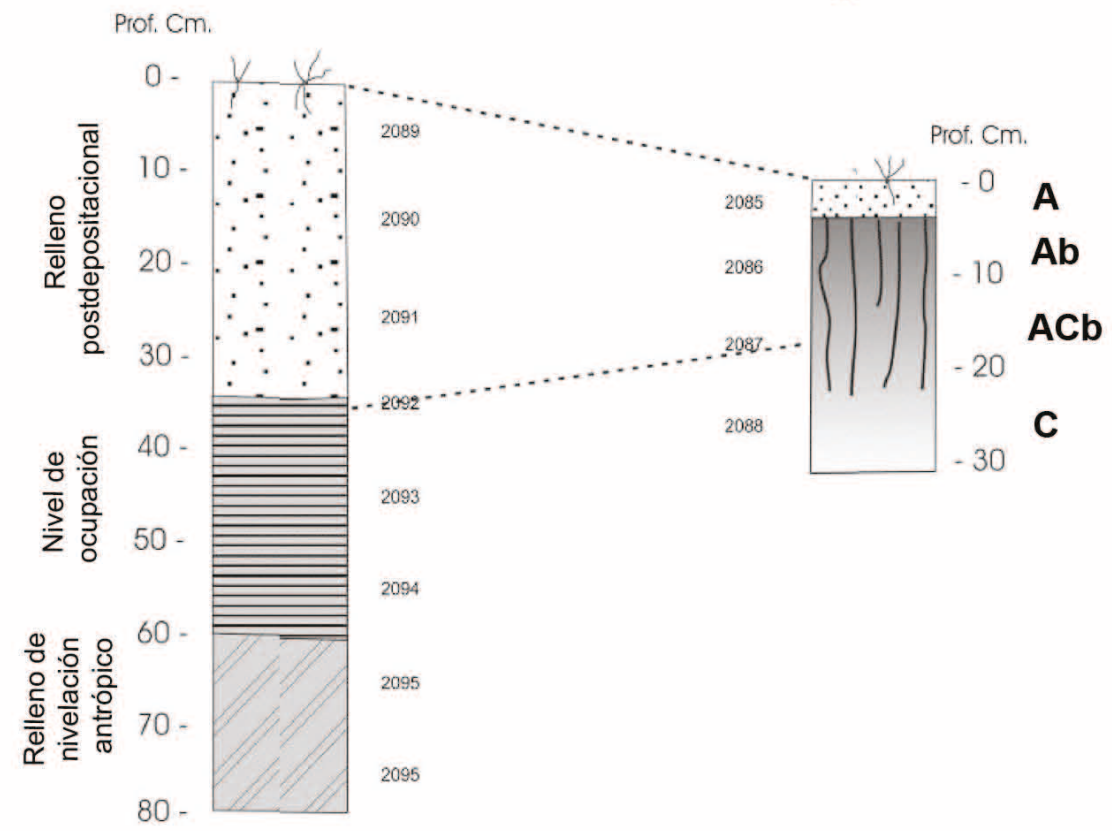

Figura 4. (1) Análisis multivariados de las asociaciones fitolíticas: A) Cluster analysis (mediante el coeficiente de correlación) de las muestras del PR; B) Análisis de correspondencia (DCA) de las asociaciones fitolíticas de ambos perfiles. (2) Correlación de ambos perfiles con base en las asociaciones fitolíticas.

relleno del PR (2095 y 2096), estos análisis los vinculan con la muestra 2094.

\section{DISCUSIÓN}

\section{Procesos de formación e interpretación botánica del PS}

La primera y más evidente modificación antrópica de este perfil está representada por los alineamientos de piedra subparalelos entre sí, semienterrados en el perfil, que delimitan el suelo cultivado. Como ya se indicó, el análisis estratigráfico mostró la presencia de dos ciclos pedológicos: el reciente, representado por un horizonte $A$, con marcadas diferenciaciones de los horizontes $\mathrm{Ab}-\mathrm{A} /$ Cb-C subyacentes. Los valores de materia orgánica y fósforo también permiten reconocer que el ciclo pedológico inferior presenta un mayor desarrollo, vinculado a la etapa de producción agrícola. El bajo 
nivel de fósforo en el horizonte $\mathrm{Ab}$ puede vincularse al aprovechamiento intensivo de este suelo.

El registro de microfósiles en el PS también presenta una discontinuidad entre la unidad superior y el paleosuelo indicado por un cambio en las proporciones de los diferentes microvestigios; asimismo, muestra una composición empobrecida en los materiales parentales (muestra 2088) y un enriquecimiento en las muestras suprayacentes.

En términos generales, el material parental de este suelo, representado por las muestras inferiores, demarcaría la presencia de una flora caracterizada por elementos pooideos y estipoideos vinculados a condiciones ambientales mas frías. Estos paleoindicadores presentan un marcado cambio en la muestra 2086, con la disminución de los elementos pooideos y estipoideos, y un incremento de los elementos graminoides megatérmicos (panicoides y chloridoides), como así también de dicotiledóneas. Esto permite interpretar condiciones, naturales o antropizadas, más benignas para el desarrollo de cultivos. En la asociación de la muestra superficial (2085) se observa mayor abundancia de elementos vegetales xéricos, por una parte, como así también una mayor representación de otros morfotipos como los globulares espinosos, las sillas de montar colapsadas y las de contorno rectangular.

Los resultados más significativos desde el punto de vista arqueológico corresponden a los niveles inferiores de la secuencia (muestras 2086, 2087 2088), dado que se pudieron identificar procesos o eventos que en una primera interpretación quedaban enmascarados por el mismo desarrollo del suelo. La presencia de diatomeas en la muestra 2086 y su ausencia neta en las unidades inferiores, la aparición de microcarbones a partir de la muestra 2087, y la clara diferenciación de las asociaciones fitolíticas que segrega el horizonte $\mathrm{Ab}$ de los horizontes $\mathrm{A} / \mathrm{Cb}$ y $\mathrm{Cb}$ son diferencias que no pueden explicarse solamente teniendo en cuenta los procesos naturales de formación de suelos. El incremento del contenido de fósforo en el horizonte $\mathrm{A} / \mathrm{Cb}$ (muestra 2087), conjuntamente con el aumento de microcarbones, podría evidenciar en su conjunto una mayor incorporación de materia orgánica parcialmente degradada, compatible con un momento anterior a la explotación agrícola y específicamente a las actividades peridomésticas asociadas a la U48-R3.

Por otro lado, la presencia de diatomeas en el horizonte Ab (muestra 2086) podría indicar un riego antrópico, de modo similar a lo registrado por Korstanje (2010) en otros sitios agrícolas del NOA.

Para finalizar, se destaca que en los niveles superiores existe un marcado incremento en la variedad y abundancia de los fitolitos panicoides, y una mayor presencia de fitolitos bilobados y los de forma de cruz, con algunas formas que pueden estar vinculadas con la presencia de maideas.

\section{Procesos de formación e interpretación botánica del PR}

Como se indicó, la estratigrafía del PR incluye una sección basal que representa un relleno de nivelación -representado por las muestras 2095 y 2096-, una sección media que abarca los niveles de ocupación -con un primer nivel de mezcla (2094)-, y finalmente los depósitos recientes suprayacentes. Respecto de la presencia de fitolitos, a grandes rasgos hay, en todo el perfil, indicios de elementos estipoides, pooides-festucoides, chloridoides, panicoides, danthonioides y bambusoides.

En forma particular, cabe destacar la presencia de fitolitos más o menos redondeados en sección, de gran a mediano tamaño, con sus superficies cavadas (Figura $2 \mathrm{CAV}$ ), presentes en la asociación de la muestra 2094, que, conjuntamente con distintos tipos de morfotipos poliédricos -los originados en elementos de conducción, en forma de abanico, halterios panicoides y los de forma de conos truncados- caracterizan a esta muestra y, en menor medida, a la suprayacente. Este morfotipo en particular ha sido referido a la familia de las Cucurbitaceae (Piperno 2006 y referencias allí citadas), a la que pertenecen las calabazas y los zapallos.

Respecto de los fitolitos globulares de superficie espinosa, pueden considerarse las típicas estegmatas de palmeras (entre 5-25 $\mu \mathrm{m}$ de diámetro, sensu Patterer 2014), las de tamaño intermedio (o tipo Bromeliaceae, sensu Benvenuto et al. 2015), como así también podrían incluirse los fitolitos de menor tamaño multifacetados. Estos últimos, considerados rugulosos o de superficies irregulares según algunos autores (spherical irregularly folded sensu Thorn 2001; druses-like, sensu Prychid et al. 2004; Chen y Smith 2013; Costus/Canna [Zingiberales] phytoliths p.p. sensu Strömberg et al. 2013), se presentan en distintos grupos de Zingiberales tales como las Marantaceae, Cannaceae y Zingiberaceae (Prychid et al. 2004; Piperno 2006; Benvenuto et al. 2015). En los perfiles analizados, los fitolitos 
globulares espinosos (Figura 2, GLS) se encontraban en los rangos de tamaños mayores e intermedios, lo cual implica la presencia de indicadores no solo de Bromeliaceae, sino también de elementos asignables a Arecaceae, los cuales, si bien en poca cantidad, se encontraron presentes en los niveles superiores del PS y en la sección vinculada con la ocupación del PR. Estos pueden tener vinculación a la existencia de Trithrinax schyzophylla en las laderas bajas y parte del piedemonte del chaco serrano (Morláns 1995), e interpretamos que su presencia podría ser indicador de objetos de cestería, por ejemplo. De similar distribución estratigráfica se pueden mencionar los fitolitos en forma de sillas de montar colapsadas (Figura 2, BAMSAD), asignables a bambusoideas (sensu Piperno y Pearsall 1998), ya que en la flora regional solo se halló este componente (representado por Chusquea lorentziana) en la zona del distrito de las Selvas montanas de la provincia de las Yungas (Morláns 1995), y de tener estas afinidades botánicas, su presencia solo puede ser explicada mediante acción antrópica, como por ejemplo, su utilización como parte del techo del recinto.

Otro morfotipo muy vinculado con los demás indicadores chloridoideos son las sillas de montar de contornos rectangulares (Figura 2, RECSAD). Este ha sido recientemente descripto para Lycurus setosus (Zucol et al. 2019), presente en la vegetación regional.

Respecto de la presencia de diatomeas, si bien en general son elementos pequeños, que pueden vincularse a cuerpos o acumulaciones de agua temporarios, se encuentran presentes en todo el $P R$, mientras que en el PS solo fueron registradas en las muestras superficiales. El PR presentó además, principalmente en su sección media, distintos elementos de los géneros Pinnularia, Rhopalodia y Epithemia, las cuales crecen en cuerpos de agua con vegetación sumergida a la que se adhieren estas algas, que en general corresponden a medios pobres en nitrógeno. En la sección superior, estos organismos pueden haberse originado durante la formación de pequeños cuerpos de agua resultantes de la inundación del recinto tras las lluvias y su posterior desecamiento. Pero en los niveles de ocupación, creemos que la presencia de diatomeas relacionadas con cuerpos de agua es el resultado de prácticas antrópicas tales como la introducción de agua para apelmazar del piso.

\section{Correlación estratigráfica y sucesión de eventos}

El análisis conjunto de las asociaciones fitolíticas de las muestras de los dos perfiles (Figura 4.1.B) permite observar una diferenciación de ambos grupos de muestras superficiales entre el PS (2085 y 2086) y del PR (2089), las cuales, si bien guardan similitud respecto de elementos composicionales, difieren respecto de la abundancia de morfotipos. La muestra 2087 del PS (horizonte $\mathrm{A} / \mathrm{Cb}$ ) es la que presenta mayor afinidad con las asociaciones de la sección media e inferior del PR y particularmente con la muestra 2092 (piso de ocupación). Por lo cual, es el horizonte $\mathrm{A} / \mathrm{Cb}$ el que resultó correlacionable composicionalmente con los niveles de ocupación del PR (Figura 4.2). Dadas las características composicionales, que varían de una vegetación dominada por estipoideas, festucoides y pooideas -las cuales dejan de ser predominantes en el horizonte Ab y se ven reemplazadas por la abundancia de panicoideas, chloridoideas y dicotiledóneas-, es que se puede estimar que la vegetación que aportó estos fitolitos era natural o bien la resultante del área peridoméstica; la que cambia en niveles suprayacentes como consecuencia del reacondicionamiento para uso agrícola. La presencia de microcarbones en los niveles inferiores (y su baja en el horizonte Ab), al igual que la caída abrupta del contenido de fósforo, ratifican nuestra interpretación, además de la presencia de diatomeas en los niveles superiores, junto con el marcado incremento de fitolitos en forma de cruces y halterios panicoides.

Cabe destacar que la diferencia existente entre la potencia de cada una de las unidades estratigráficas del interior de la estructura residencial -mucho más potentes en comparación con las estructuras agrícolas, que resultan de diferentes procesos de sedimentación y erosión- no permitió correlacionarlas en forma directa.

En síntesis, las unidades estratigráficas registrarían los siguientes momentos, de mayor a menor antigüedad (Figura 5):

1) Superficie sin modificación antrópica significativa, representada por el material parental del PS.

2) Construcción y habitación de la U48, representada por la arquitectura del recinto y su piso de ocupación, cuyo fechado $1394 \pm 39$ AP correspondería a la última etapa de su uso. En el exterior del recinto se observan indicios de actividades peridomésticas.

3) Abandono de la estructura habitacional, comienzo de la sedimentación dentro y fuera del recinto 

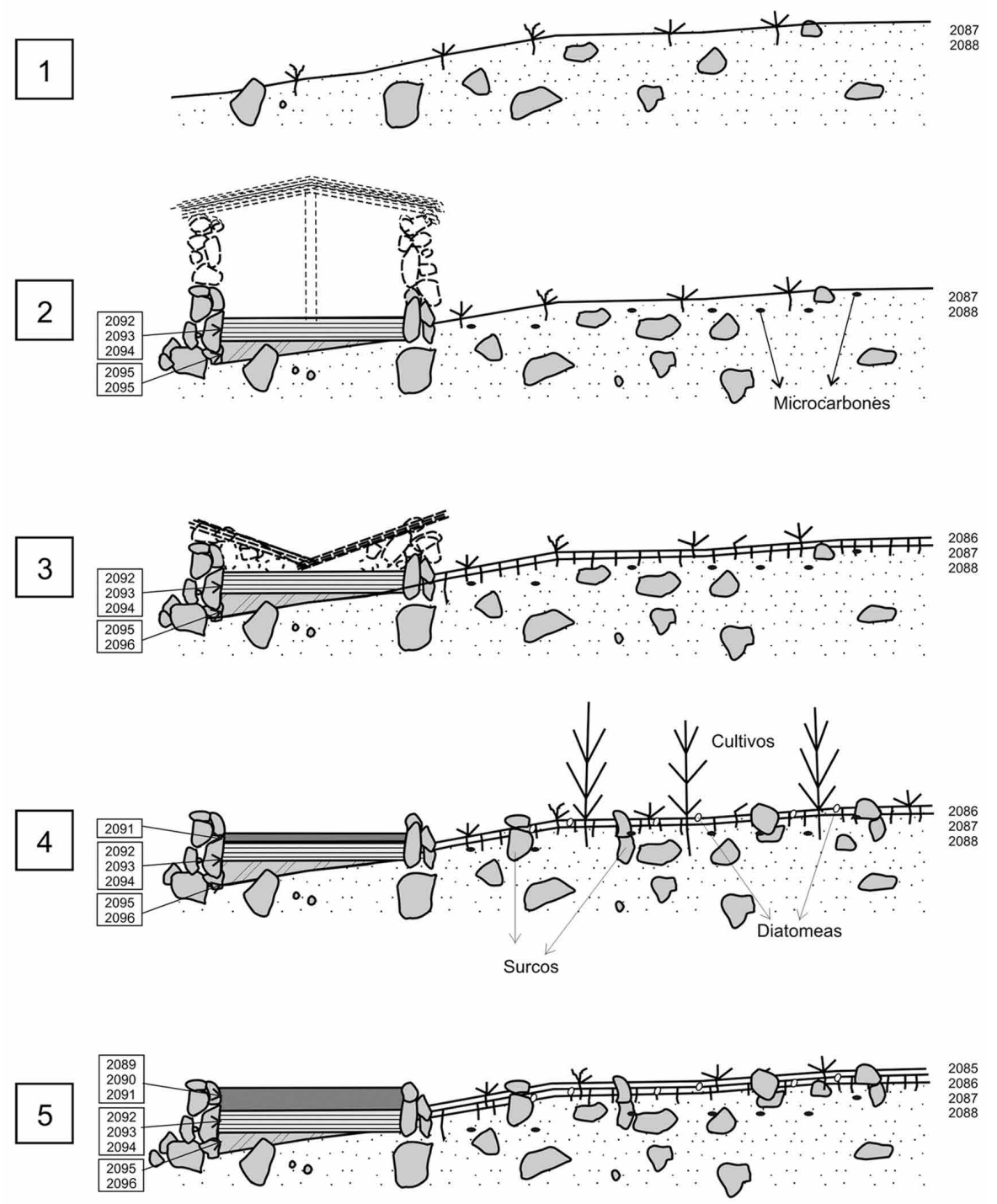

Figura 5. Esquema de la secuencia de eventos inferida para la U48-R3 y las estructuras agrícolas adyacentes.

y de mayor pedogénesis en la superficie exterior.

4) Acondicionamiento y utilización agrícola del área

del PS. Depositación de sedimentos de relleno al interior del recinto y presencia de vegetación sin mayores influencias antrópicas.

5) Fin de la explotación agrícola y sepultamiento del suelo, cambios que también se observan con diferentes características en el PR.

Esta secuencia de eventos es coherente con los rasgos arquitectónicos registrados. Nótese que los muros de la pared de la U48-R3 no tienen más que una o dos hiladas de piedra por sobre los cimientos, de modo que es posible que las rocas que formaban parte de las paredes hayan sido reutilizadas como insumo para la construcción de las estructuras que delimitan los surcos de cultivo.
Respecto de la cronología de la construcción y de la utilización de las estructuras de cultivo, podría asociarse al momento de uso de la represa arqueológica registrada a menos de 300 $\mathrm{m}$ de distancia, cuyo fechado indica $642 \pm 42$ AP. El agua de esta represa podría haber sido la fuente de origen de gran parte de los microrrestos de espongiarios y diatomeas registrados en las estructuras agrícolas.

\section{CONCLUSIONES}

El análisis de los procesos de formación vinculados a cada uno de los perfiles analizados, junto con la correlación que puede establecerse en su contenido de microfósiles, permite establecer una historia diferente a la propuesta por Arocena y colaboradoras (1960), quienes habían propuesto la contemporaneidad de ambos tipos de estructuras y su asociación al período temprano. La información presentada permite proponer que el nivel de ocupación de la unidad residencial U48-R3 es anterior a la construcción y utilización de las estructuras formadas por las líneas de piedra que delimitan los surcos de cultivo, de modo que no existe contemporaneidad en el pleno uso de ambas. En el piso de ocupación de la unidad residencial se destaca el hallazgo de evidencias de cucurbitáceas; arecáceas y bambusoideas, todas ellas introducidas antrópicamente para algún fin.

Los microrrestos del material parental PS evidenciaron un área peridoméstica indistinguible desde la arquitectura. Los microfósiles del suelo agrícola indicaron condiciones ambientales más benignas, utilización de agua para riego y el posible cultivo de maíz. 
Como corolario, es importante destacar que la articulación entre análisis estratigráfico y de microfósiles para correlacionar una unidad doméstica y las estructuras agrícolas adyacentes resultó exitosa, y abre nuevas aplicaciones del estudio de microrrestos silíceos en contextos arqueológicos, y nuevas precauciones para la interpretación de la arquitectura en superficie.

\section{Agradecimientos}

Esta investigación se financió mediante el PICT 0345-2014, dirigido por Myriam Tarragó. Agradecemos a Gabriel Acuña Suarez, Mirta Arriaga y María Gabriela Fernández Pepi por su colaboración.

\section{REFERENCIAS CITADAS}

Albeck, M. E.

2003-2005 Sitios agrícolas prehispánicos: la búsqueda de indicadores cronológicos y culturales. Cuadernos del INAPL 20: 13-26.

Ambrosetti, J. B.

1897 La antigua Ciudad de Quilmes (Valle Calchaquí). Boletín del Instituto Geográfico XVIII (1, 2 y 3): 1-17.

Ardissone, R.

1928 Coctaca. Anales de la Sociedad Argentina de Estudios Geográficos III (1): 161-166.

Arocena, M. L., G. de Gásperi y S. Petruzzi

1960 Caspinchango. En Investigaciones arqueológicas en el Valle de Santa María, pp. 81-109. Universidad Nacional del Litoral, Rosario.

Belotti, C. R.

2013 Usos económicos y rituales de la fauna en la región valliserrana del Noroeste argentino entre los inicios del periodo Temprano y hasta la conquista. Tesis Doctoral inédita. Facultad de Filosofía y Letras, Universidad de Buenos Aires, Buenos Aires.

Benvenuto, M. L., M. Fernández Honaine, M. L. Osterrieth y E. Morel

2015 Differentiation of globular phytoliths in Arecaceae and other monocotyledons: morphological description for paleobotanical application. Turkish Journal of Botany 39. doi:10.3906/bot-1312-72

Berberián, E. y A. Nielsen

1988 Sistemas de asentamiento prehispánicos en el Valle de Tafí. Comechingonia, Córdoba.
Bonomo, M., A. F. Zucol, B. Gutiérrez Tellez, A.

Coradeghini y M. S. Vigna

2009 Late Holocene Palaeoenvironments of the Nutria Mansa 1 Archaeological Site, Argentina. Journal of Paleolimnology 41 (2): 273-296.

Bruch, C.

1911 Exploraciones arqueológicas en las provincias de Tucumán y Catamarca. Coni, Buenos Aires.

Cabrera, A. L. y A. Willink

1980 Biogeografía de América Latina. Serie Biología 13. Organización de Estados Americanos, Washington.

Carbonelli, J. P

2012 Secuencia de producción lítica en el sitio Mesada del Agua Salada, Caspinchango, Valle de Yocavil. Revista Española de Antropología Americana 42 (2): 359-382.

Chen, S. T. y S. Y. Smith

2013 Phytolith variability in Zingiberales: A tool for the reconstruction of past tropical vegetation. Palaeogeography, Palaeoclimatology, Palaeoecology 370: 1-12.

Collura, L. V. y K. Neumann 2016 Wood and bark phytoliths of West African woody plants. Quaternary International 434 (Part B): 142-159.

Criado Boado, F.

1991 Construcción social del espacio y reconstrucción arqueológica del paisaje. Boletín de Antropología Americana 24: 5-29.

Debenedetti, S.

1918 Las ruinas prehispánicas de El Alfarcito (Departamento de Tilcara, Prov. de Jujuy). Boletín de la Academia Nacional de Córdoba XXIII: 283-318.

Garralla, S

2003 Análisis polínico de una secuencia sedimentaria del Holoceno Tardío en el Abra del Infiernillo, Tucumán, Argentina. Polen 12: 53-63.

González, A. R.

1955 Contextos culturales y cronología relativa en el área central del N.O. Argentino (Nota preliminar). Anales de Arqueología y Etnología XI: 7-32.

González, O., M. E. Viruel, R. Mon, P. Tchilingurian y E. Barber

2000 Hoja Geológica 2766-II San Miguel de Tucumán. Boletín del Programa Nacional de Cartas Geológica de la República Argentina 1:250000, № 245. SEGEMAR, Buenos Aires. 
Grimm, E. C.

1987 CONISS: a FORTRAN 77 program for stratigraphically constrained cluster analysis by the method of incremental sum of squares. Computers \& Geosciences 13 (1): 13-35.

Hammer, O., D. A. T. Harper y P. D. Ryan

2001 PAST: Paleontological Statistics Software Package for Education and Data Analysis. Palaeontologia Electronica 4 (1): 1-9.

Hill, M. O. y H. G. Gauch Jr.

1980 Detrended Correspondence analysis: an improved ordination technique. Vegetatio 42: 47-58.

Korstanje, M. A.

2010 Microfósiles y agricultura prehispánica: Primeros resultados de un análisis múltiple en el N.O.A. En Análisis fitolíticos de vegetación, suelos y sedimentos en sitios arqueológicos: estado actual de su conocimiento en América del Sur, editado por A. F. Zucol, M. Osterrieth, M. Brea y N. Borrelli, pp. 249263. Universidad Nacional de Mar del Plata, Mar del Plata.

Korstanje, M. A. y M. P. Babot (editoras) 2008 Matices interdisciplinarios en estudios fitolíticos y de otros microfósiles. BAR International Series 1870. Archaeopress, Oxford.

Korstanje, M.A., P. Cuenya y V. Williams 2010 Taming the control of chronology in ancient agricultural structures. Non traditional data sets. Journal of Archaeological Science 37: 343-349.

Korstanje, M.A., P. Cuenya y M. Maloberti 2014 El análisis múltiple de microfósiles como herramienta para estudiar paisajes agrícolas y prácticas campesinas: una síntesis metodológica. En Avances y desafíos metodológicos en arqueobotánica: Miradas consensuadas y diálogos compartidos desde Sudamérica, editado por C. Belmar y V. Lema, pp. 252-275. Universidad SEK, Santiago de Chile.

Lanzelotti, S. L.

2011 Indicadores para el reconocimiento de represas arqueológicas. Relaciones de la Sociedad Argentina de Antropología XXXVI: 177-196.

2012 Uso del espacio y construcción del paisaje agrícola en la cuenca del río Caspinchango (Valle de Yocavil, Catamarca). Tesis Doctoral inédita. Facultad de Filosofía y Letras, Universidad de Buenos Aires, Buenos Aires.

Lanzelotti, S. L. y M. Lamamí

2010 Cálculo de capacidad de riego e infiltración en represas y surcos prehispánicos de Caspinchango (provincia de Catamarca. En La arqueometría en
Argentina y Latinoamérica, pp. 385-390. Editorial de la Facultad de Filosofía y Humanidades, Córdoba.

Lanzelotti, S. L. y R. C. Spano

2015 La multitemporalidad del paisaje en la Mesada del Agua Salada. Arqueología, 21 (1): 47-71.

Mercader, J., T. Bennett, C. Esselmont, S. Simpson y D. Walde

2009 Phytoliths in woody plants from the Miombo woodlands of Mozambique. Annals of Botany 104: 91-113.

Mercader, J., F. Astudillo, M. Barkworth, T. Bennett, C. Esselmont, R. Kinyanjui, D. L. Grossman, S. Simpson y D. Walde

2010 Poaceae and Cyperaceae phytoliths from the woodlands of Niassa Rift, Mozambique. Journal of Archaeological Science 37: 1953-1967.

Morláns, M. C.

1995 Regiones Naturales de Catamarca. Provincias Geológicas y Provincias Fitogeográficas. Revista de Ciencia y Técnica 2: 1-42.

Morrone, J. J. y C. Ezcurra

2016 On the Prepuna biogeographic province: A nomenclatural clarification. Zootaxa 4132: 287-289.

Neumann, K., A. G. Fahmy, N. Müller-Scheeßel y M. Schmidt

2016 Taxonomic, ecological and palaeoecological significance of leaf phytoliths in West African grasses. Quaternary International 434B: 15-32.

Núñez Regueiro, V.

1974 Conceptos instrumentales y marco teórico en relación al análisis del desarrollo cultural del noroeste argentino. Revista del Instituto de Antropología 5: 169-190.

Patterer, N. I.

2014 Análisis fitolíticos de las principales especies de palmeras (Arecaceae) presentes en regiones subtropicales de América del Sur. Boletín de la Sociedad Argentina de Botánica 49: 491-502.

Pearsall, D. M.

1978 Phytolith Analysis of Archaeological Soils: Evidence for Maize Cultivation in Formative Ecuador. Science 199: $177-178$.

Peña-Monné, J. L., C. Sancho, M. M. Sampietro-Vattuone, F. Rivelli, E. J. Rhodes, M. C. Osacar-Soriano, V. Rubio-

Fernández y R. García-Giménez

2015 Environmental change over the last millennium recorded in the Cafayate Dune field (NW Argentina). Palaeogeography, Palaeoclimatology, Palaeoecology 438: 352-363. 
Piperno, D. R.

2006. Phytoliths. A comprehensive guide for archaeologists and paleoegologists. Altamira, Oxford.

Piperno D. R. y D. M. Pearsall

1998 The Silica Bodies of Tropical American Grasses: Morphology, Taxonomy, and Implications for Grass Systematics and Fossil Phytolith Identification. Smithsonian Contributions to Botany 85.

Prychid, C. J., P. J. Rudall y M. Gregory 2004 Systematics and biology of silica bodies in Monocotyledons. The Botanical Review 69: 377-440.

Ruiz Huidoro, O.

1972 Descripción Geológica de la Hoja 11e, Santa María. Provincia de Catamarca y Tucumán. Carta Geológico-Económica de la República Argentina. Escala 1:200000. Boletín No 134. SEGEMAR, Buenos Aires.

Sampietro Vattuone, M. M., J. L. Peña Monné, J. Roldán y M. G. Maldonado

2014 Reconstruction of agrarian practice and land impact in the drylands: A geoarchaeological approach. European Geologist 38: 5-8.

Scattolin, M. C.

2007 Santa María antes del año mil. Fechas y materiales para una historia cultural. En Sociedades precolombinas surandinas. Temporalidad, interacción y dinámica cultural del NOA en el ámbito de los Andes Centro-Sur, editado por V. I. Williams, B. N. Ventura, A. B. M. Callegari y H. D. Yacobaccio, pp. 203-219. Instituto de Ciencias Antropológicas, Buenos Aires.

Soil Survey Staff

1999 Soil Taxonomy: A basic System of Soil Classification for making and interpreting Soil Survey, 2da. ed. United States Department of Agriculture, Soil Conservation Service, Washington.
Strömberg, C. A. E., R. E. Dunn, R. H. Madden, M. J.

Kohn, y A. A. Carlini

2013 Decoupling the spread of grasslands from the evolution of grazer-type herbivores in South America. Nature Communications 4: 1478.

Thorn, V. C.

2001 Oligocene and Early Miocene Phytoliths from CRP-212A and CRP-3, Victoria Land Basin, Antarctica. Terra Antartica 8: 407-422.

Walanus, A. y D. Nalepka

1999 POLPAL. Program for counting pollen grains, diagrams plotting and numerical analysis. Acta Damalaeobotanica Suppl. 2: 659-661.

2002 POLPAL. Counting pollen, tables storage and diagrams plotting. System manual. Polish Academy of Sciences. Polonia.

Waters, M. R.

1992 Principles of Geoarchaeology. A North American Perspective. The University of Arizona Press, Tucson.

Zucol, A.F., M. Brea y E. Passeggi

2008 Los estudios fitolíticos en América del Sur, una visión retrospectiva. En Matices interdisciplinarios en estudios fitolíticos y de otros microfósiles, editado por A. Korstanje y P. Babot, pp. 3-21. BAR International Series S1870. Archaeopress, Oxford.

Zucol, A. F., N. I. Patterer, E. Moya y M. G. Fernández Pepi

2019 Phytolith analysis of the main species of Distichlis sp. (Chloridoideae: Poaceae) distributed in South America. Review of Palaeobotany and Palynology. En prensa. 